\title{
Resenha de Barros (2015) Relações de gênero na literatura de cordel
}

\author{
Marcos Antonio Batista da Silva \\ Centro de Estudos Sociais (CES) - Universidade de Coimbra, Portugal
}

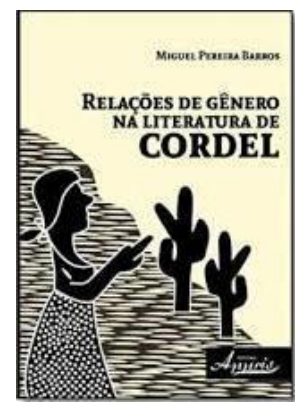

Miguel Pereira Barros, autor do livro "Relações de gênero na literatura de cordel", possui graduação em Psicologia pela Universidade Federal de Alagoas e mestrado em Psicologia Social, pela Pontifícia Universidade Católica de São Paulo (PUC-SP). O livro é originário da dissertação de mestrado do autor, intitulada "O masculino e o feminino na literatura de cordel publicada em São Paulo", defendida no ano de 2014 na PUC-SP. Segundo Miguel Barros, a literatura de cordel é um tema relativamente novo no campo da Psicologia Social, haja vista que em suas buscas o autor localizou poucos estudos voltados para essa temática em sua revisão de literatura.

Para Miguel Barros estudar a literatura de cordel foi uma inserção na história de sua própria cultura, uma vez que o cordel é uma expressão muito interessante no que se refere à cultura popular, sendo muitas vezes retratado na mídia de forma estereotipada,
Barros, Miguel Pereira (2015). Relações de gênero na literatura de cordel. Curitiba: Appris.

ISBN: 978-8581928562 mobilizou o autor a estudá-lo, e conhecê-lo em São Paulo.

Ao se inserir na literatura de cordel o autor discute, e analisa discursos referentes a relações de gênero na publicação de literatura de cordel. Isto é, o autor descreve e interpreta discursos referentes ao masculino e ao feminino na literatura de cordel, contextualizando as condições de produção de folhetos publicados na cidade de São Paulo, Brasil, a partir das origens do gênero literário da poesia de cordel, produzidas nos estados no Nordeste brasileiro desde o final do século XIX, e levados a São Paulo devido aos movimentos de migração interna no país.

$\mathrm{Na}$ introdução do livro, Miguel Barros assinala que os folhetos de cordel foram cultivados inicialmente, em terras europeias, sobretudo na península ibérica, lembrados na Espanha como pieglos sueltos, conhecidos em Portugal pelo nome de "folhas soltas", os folhetos de 
cordel começaram a circular no Brasil durante o período da colonização portuguesa, apresentando características medievais no uso de uma linguagem rebuscada e formal, aliando com constância o real e o lendário.

Miguel Barros, na esteira de Oliveira (2012), assinala que no Brasil, a denominação literatura de cordel teve início, no final do século XIX. O cordel era considerado como um tipo de literatura feita pelo povo e não para o povo, como sendo o mesmo que era publicado em Portugal e, tendo em vista a competição da literatura de cordel com a publicação de jornais temia-se por seu desaparecimento. Mas não foi, porém, isso que aconteceu, pois, durante o século XX e início do XXI, a literatura de cordel reinventou-se na interação com os novos tempos. Onde a comercialização do cordel, no começo do século XX, era realizada nas feiras populares, especialmente, do Nordeste do país, com a disposição dos folhetos pelo chão ou em maletas de madeira, um modo de exposição prático de ser montado e desmontado. As vendas eram efetuadas através da recitação dos versos pelo poeta.

A literatura de cordel no Brasil tornou-se um gênero literário com suas características únicas de métrica, rima e textos desenvolvidos em linguagem coloquial. De origem portuguesa, a literatura de cordel no Brasil, só começou ser publicada comercialmente nos fins do século XIX em pequenas tipografias na cidade do Recife, PE. Contudo, ao atingir o contexto dos grandes centros, essas práticas comunitárias de leitura foram perdendo a sua funcionalidade, levando os leitores a praticarem uma leitura silenciosa, predominante até os dias atuais. Na contemporaneidade é possível encomendar-se folhetos de cordel pela internet (século XXI) que são entregues em domicílio, inclusive de heroínas negras na história do Brasil.

Voltando seu olhar para São Paulo, objeto de estudo do autor, adentrando na contemporaneidade, nos anos 2000, Miguel Barros nos revela que os cordelistas em São Paulo atuam em bibliotecas variadas e centros comunitários como, por exemplo, a Biblioteca Belmonte, no bairro de Santo Amaro. Tem sido produzida, publicada e difundida uma profícua produção de folhetos de cordel pela Editora Luzeiro. Nesse contexto, Miguel Barros localizou 311 títulos, de autores residentes, tanto no Nordeste como em São Paulo para sua pes- quisa. Dentre os autores, foi observada uma minoria de mulheres e nos títulos uma maioria de referências ao masculino. Desse modo o autor questiona: que configurações associam o masculino e o feminino nesta literatura de cordel de origem nordestina, publicada na cidade de São Paulo?

O capítulo 1, intitulado “Teorias e Método", concentra-se nas teorias que embasaram a pesquisa do autor: teoria da ideologia de John B. Thompson (2009), e de gênero proposta pela historiadora Joan Scott (1995). No que se refere à primeira teoria, Miguel Barros, na esteira de Thompson (2009) assinala a relevância da midiação da cultura na construção da modernidade e a importância decorrente dos estudos sobre ideologia.

Thompson (2009) utiliza alguns conceitoschave para subsidiar a sua análise: sentido, dominação, e os modos de operação da ideologia na sustentação e manutenção de relações de dominação. O autor, primeiramente, compreende sentido com base nas formas simbólicas (falas, textos, ações, imagens, entre outras) produzidas, reproduzidas e sustentadas pelos sujeitos nos contextos sociais estruturados em que vivem e no mundo social no qual circulam.

Em seguida define "dominação" como relações de poder sistematicamente assimétricas, ou seja, aquelas pelas quais um grupo detém poder de modo permanente e significativo, impedindo ou limitando ao outro o acesso a esse poder. Thompson (2009) situa o seu estudo sobre ideologia no contexto da midiação da cultura moderna. E assinala que esse processo favoreceu mudanças na transmissão, produção e circulação das formas simbólicas, cada vez mais mediadas pelos veículos da mídia.

A midiação da cultura moderna ocorreu paralelamente à expansão do capitalismo industrial e às formações dos estados-nação, afetando, profundamente, o comércio e as interrelações entre as sociedades. Nesse sentido, ocorreu um crescimento nas relações comerciais e a expansão das transmissões das formas simbólicas a um nível global por meio dos veículos midiáticos, tais como, livros didáticos, jornais, rádios, TV, internet, folhetos de cordel, entre outros.

$\mathrm{Na}$ segunda teoria, baseada nos estudos de gênero, Miguel Barros recorre aos aportes 
teóricos de Joan Scott (1995), uma das autoras que tem atentado para a análise das relações de gênero enquanto relações de poder e apresenta um resgate histórico dos usos do termo gênero, apreendendo as formas como ele começou a ser utilizado pelas historiadoras feministas que a precederam. Nessa trajetória histórica, Scott (1995) apreende dois usos principais do termo: um uso descritivo no qual o termo gênero era usado como sinônimo de mulheres e um analítico, quando o termo era usado analiticamente, como categoria social imposta sobre um corpo sexuado. Embora esses estudos delimitassem um novo campo de pesquisas com temas relevantes sobre mulheres, crianças e família, apontando para o fato de que as relações entre os sexos são sociais, não conseguiam explicar as razões pelas quais elas são construídas, seu funcionamento ou forma de mudança. “Gênero' é um novo tema, um novo domínio da pesquisa histórica, mas não tem poder analítico suficiente para questionar (e mudar) os paradigmas históricos existentes" (Scott, 1995, p. 76).

Segundo a revisão efetuada pela autora, focada na pesquisa histórica, a perspectiva analítica das historiadoras se traduzia em três posições teóricas de análise: teoria do patriarcado, tradições marxistas, associações ao pós-estruturalismo francês e às teorias angloamericanas das relações de objeto com inspirações nas tradições psicanalíticas. Scott (1995) mostra, em cada uma delas, limitações que dificultam a sua apropriação pelos estudos de gênero.

Nas teorias do patriarcado, a limitação indicada se refere à explicação da dominação apenas pelos aspectos físicos, enfatiza-se o controle do trabalho reprodutivo e a objetivação sexual da mulher pelo homem, como se outros fatores não interferissem nessa relação, o que a transforma em a-histórica e fixa. Por sua vez, nas teorias vinculadas às tradições marxistas, o problema estaria na ausência de um campo próprio de análise para o gênero, uma vez que as desigualdades eram vistas como resultantes das relações econômicas de exploração. No caso das teorias baseadas nas escolas psicanalíticas, o equívoco estaria na limitação das relações entre homem e mulher ao âmbito familiar, sem expandir para outros campos ou explicações.

Por fim, neste capítulo Miguel Barros faz uma rápida entrada no tema da violência, devido a esta ser a grande temática encontrada ao longo da análise do autor. Nesse tópico Miguel Barros aborda uma das formas de violência que vem sendo bastante discutida nos últimos anos na sociedade contemporânea, especialmente no Brasil: a violência de homens contra as mulheres.

No campo metodológico Miguel Barros utiliza a metodologia da Hermenêutica de Profundidade proposta por John B. Thompson, dedicada a captar os modos pelos quais as formas simbólicas são produzidas, circuladas e recebidas em contextos sociais concretos.

O capítulo 2, "Contexto Sócio-Histórico: A literatura de cordel no Brasil", Miguel Barros apresenta os campos de estudos de literatura e gênero, o contexto sócio-histórico de formação do gênero editorial dos folhetos da literatura de cordel e o seu desenvolvimento no Brasil. Assim, discute o cordel e seus estudos no país; as origens do cordel no nordeste brasileiro; o cordel contemporâneo e a migração para São Paulo; literatura de cordel e ideologia; as mulheres e relações de gênero no cordel. Em seguida, é exposto como o cordel está sendo apreendido na atualidade e o que dizem os estudos, contextualizando as manifestações do cordel em São Paulo. Além de mostrar as características predominantes de produções acadêmicas brasileiras referentes à literatura de cordel e relações de gênero (1987-2012) e os seus resultados.

o capítulo 3, "Análise Formal" é o mais extenso e apresenta na primeira parte os procedimentos para a constituição do corpus da pesquisa e as estratégias de análise. $\mathrm{Na}$ segunda parte apresenta os resultados. Isto é, mostra a descrição dos dados: o contexto de produção, a obra e seu produtor. Miguel Barros dá ênfase à descrição da violência e o seu impacto para as capas dos folhetos de cordel, as histórias e os protagonistas. É abordada também, entre os protagonistas, as personagens mulheres transgressoras, isto é, aquelas que fugiram dos papéis estereotipados e contestaram a norma vigente.

Nas considerações finais, Miguel Barros aponta para uma maior participação masculina na equipe de produção do cordel, bem como a construção de cenários duros, caracterizada, sobretudo, pela violência, tanto para agredir quanto para se defender. Uma outra indicação do autor é que os personagens masculinos 
apresentaram características relacionadas à força, brutalidade, coragem e independências, enquanto as personagens femininas eram vistas como belas, fracas, submissas e dependentes dos homens, sendo encontrados somente quatro casos de mulheres transgressoras desse modelo. Confirma-se assim que a assimetria de gênero se mantém na produção do cordel e nos discursos propagados nas histórias.

Miguel Barros ao movimentar a bibliografia para tratar das relações de gênero na literatura de cordel, assinala que como outros estudos encontrados nessa literatura, que, apesar de ocorrer avanço com a inserção de autoras na literatura de cordel, a representação de personagens de mulheres, a migração dessa literatura para novos centros urbanos como a cidade de São Paulo, a assimetria nas relações de gênero se mantém por meio de discursos que parecem ter a predominância de valores masculinos nas histórias como a coragem, bravura e valentia, ao passo que o feminino é visto como passivo, fiel, submisso. Contudo Miguel Barros observa a ocorrência de bipolaridades, conforme quando ocorre uma disputa de poder, onde o masculino predomina frente ao feminino. Por fim, essa obra contribui para bibliografia da literatura de cordel e de gênero no país.

Diante dos resultados obtidos pelo autor, no que se refere ao masculino e o feminino na literatura de cordel publicada em São Paulo, observa-se a ausência de uma discussão da representação do negro nesta literatura, seja no que tange ao masculino ou ao feminino.
Vivemos um momento histórico contemporâneo que postula à necessidade de se discutir as relações étnico-raciais na sociedade brasileira, em função da compreensão e reconhecimentos da diversidade étnico-racial, com suas especificidades no processo de construção sociocultural e no combate ao racismo e as desigualdades raciais (Silva, 2016). Como se dá a representação social dos negros, homens e mulheres na literatura de cordel, uma produção de significativo alcance no meio popular?

\section{Referencias}

Barros, Miguel Pereira (2015). Relações de gênero na literatura de cordel. Curitiba: Appris.

Oliveira, Carlos Jorge Dantas (2012). A formação da literatura de cordel brasileira. Tese de Doutorado inédita. Universidade de Santiago de Compostela.

Scott, Joan (1995). Gênero, uma categoria útil de análise histórica. Educação \& Realidade, 20(2), 71-99. Recuperado de http://www.seer.ufrgs.br/index.php/educacaoe realidade/article/view/71721

Silva, Marcos A.B (2016).Discursos étnico-raciais de pesquisadores/as negro/as na pós-graduação: acesso, permanência, apoios e barreiras. Psicologia em Revista, 22(2), 537-540. Recuperado de http://periodicos.pucminas.br/index.php/psicol ogiaemrevista/article/view/11593

Thompson, John B. (2009). Ideologia e cultura moderna: teoria social e crítica na era dos meios de comunicação de massa. Petrópolis, RJ: Vozes.

\section{MARCOS ANTONIO BATISTA DA SILVA}

Doutor em Psicologia Social pelo Programa de Pós-Graduação em Psicologia Social da PUC/SP, Brasil. Pós-doutorando no Centro de Estudos Sociais(CES), Universidade de Coimbra, Portugal, integrante do Projeto POLITICS Políticas de antirracismo na Europa e na América Latina: produção de conhecimento, decisão política e lutas coletivas. Financiamento do European Research Council. 
DIRECCIÓN DE CONTACTO

marcos.psico@yahoo.com.br

\section{FORMATO DE CITACIÓN}

Silva, Marcos Antonio Batista da (2018). Resenha de Barros (2015) Relações de gênero na literatura de cordel. Quaderns de Psicologia, 20(1), 103-107. http://dx.doi.org/10.5565/rev/qpsicologia. 1401 